\title{
Justiça complexa e educação. Uma reflexão sobre a dialectologia da justiça em educação
}

Complex justice and education. A reflection on the dialectology of justice in education

Justice complexe et éducation. Une réflexion sur la dialectologie de la justice en éducation

\section{Carlos Alberto Vilar Estêvão}

\section{OpenEdition}

\section{Journals}

Edição electrónica

URL: http://journals.openedition.org/rccs/1238

DOI: $10.4000 /$ rccs. 1238

ISSN: 2182-7435

\section{Editora}

Centro de Estudos Sociais da Universidade de Coimbra

\section{Edição impressa}

Data de publição: 1 Dezembro 2002

Paginação: 107-134

ISSN: 0254-1106

\section{Refêrencia eletrónica}

Carlos Alberto Vilar Estêvão, « Justiça complexa e educação. Uma reflexão sobre a dialectologia da justiça em educação », Revista Crítica de Ciências Sociais [Online], 64 | 2002, colocado online no dia 01 outubro 2012, criado a 03 maio 2019. URL : http://journals.openedition.org/rccs/1238 ; DOI :

$10.4000 /$ rccs. 1238

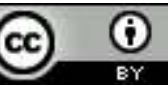




\section{CARLOS ALBERTO VILAR ESTÊVÃO}

\section{Justiça complexa e educação. Uma reflexão sobre a dialectologia da justiça em educação}

Problematiza-se o conceito de justiça, designadamente o seu sentido universalista, abstracto e formal, interpretando-o antes como pluralizado e com várias gramáticas. A partir desta contextualização, estudam-se as implicações da justiça complexa no campo da educação e, mais particularmente, nas organizações educativas. Para melhor se compreender a dialéctica da(s) justiça(s) no seio das escolas, reflecte-se, depois, sobre a natureza das organizações escolares, entendendo-as fundamentalmente como espaços "de vários mundos". Finalmente, apontam-se algumas implicações desta abordagem teórica para uma agenda ética na área da educação.

Neste texto, iremos centrar-nos fundamentalmente em três pontos: na delimitação da noção de justiça complexa tendo em vista reconhecer a sua pluralidade de acordo com as diversas esferas sociais; nas implicações deste conceito relativamente à compreensão da escola como organização, o que obrigará, entre outros aspectos, a repensá-la como constituída por vários mundos; e, finalmente, nas implicações da justiça para a organização ética das escolas e a formação dos actores educativos tendo em conta fundamentalmente a perspectiva sócio-crítica.

\section{Justiça complexa}

Parecerá quase herético tratar o conceito de justiça destituído, pelo menos aparentemente, da grandeza que lhe advém do seu carácter universal e abstracto, pairando por cima das suas variações interpretativas.

Com efeito, na linha do racionalismo e universalismo da longínqua Ilustração, a justiça deve estar vinculada a um ponto de vista universal, comum a todas as suas fórmulas concretas, que podem variar entre "a cada um a mesma coisa"; "a cada um segundo os seus méritos", "a cada um segundo as suas obras", "a cada um segundo as suas necessidades", a "cada um segundo o seu lugar ou posição" ou ainda "a cada um segundo o que a lei lhe atribui" (Perelman, 1990). Não obstante esta variedade, 
todas essas fórmulas assentam, porém, num conceito comum de justiça formal, definida como "um princípio de acção segundo o qual os seres de uma mesma categoria essencial devem ser tratados da mesma maneira" (ibid.: 30).

Outra tendência, radicada no contratualismo liberal, dá igualmente um grande relevo à justiça universalista procurando encontrar os seus princípios mínimos, que deveriam, segundo Rawls (1993), resultar de um acordo entre pessoas livres e razoáveis colocadas numa posição original, sob um "véu de ignorância" quanto a eventuais benefícios ou vantagens que pudessem retirar devido à sua condição ou posição social. Seria com base nesse acordo que emergiria a justiça enquanto "equidade" sob a qual se edificaria um original contrato social, ao mesmo tempo que ficaria definido a priori o que seria justo ou injusto, assim como se sinalizariam de antemão as regras mínimas da convivência.

Estas preocupações universalistas da justiça emergem igualmente, e entre outros autores, em Habermas, embora identificadas como legitimidade dialógica-comunicativa. Por outras palavras, este autor coloca a justiça a partir dos pressupostos que fundamentam a ética comunicativa, concebendo esta última como tratando sobretudo de "questões da justiça, isto é, questões que têm a ver com a resolução discursiva da pretensão de validade de normas problematizadas, com os conflitos de acção em definitivo" (García-Marzá, 1992: 191).

$\mathrm{Na}$ verdade, Habermas (1987) procura enquadrar o pluralismo das normas pelas exigências universais de comunicação e da discussão, afirmando que o princípio de universalidade assenta na prova pragmático-transcendental dos pressupostos gerais e necessários da argumentação implícitos em toda a acção comunicativa. A criação desta ética intenta, assim, ir além das razões empíricas ou meramente contextualizadas, visando sobretudo uma fundamentação do ponto de vista moral ou uma argumentação racional nas questões práticas, uma vez que seria a este nível que se romperia com "as validades intuitivas" dos contextos de acção (García-Marzá, 1992). Consequentemente, só por um programa de fundamentação pragmático-discursiva é que será possível chegar ao princípio moral de que as normas ou as acções ou as instituições só serão justas quando forem aceites por todos os afectados num discurso prático, sob condições perfeitas de simetria e igualdade nas oportunidades de participação (Habermas, 1997, 2001). É também este princípio ético-discursivo que se institui verdadeiramente como um princípio de legitimação democrática, o que faz, então, com que as decisões só possam descrever-se como legítimas quando merecerem a concordância de todos os implicados num procedimento democrático, em 
condições que propiciem a participação de todos, como livres e iguais, na formação da vontade discursiva (trata-se, portanto, de uma teoria da "democracia deliberativa").

Contrariamente a estas posições, outros autores têm vindo a pensar a justiça de um modo mais relativizado, ou seja, como mais vinculada a uma comunidade política concreta (com tradição e significados sociais comuns), sendo específica de cada esfera social. Concretamente, Michael Walzer (1999), um dos autores mais representativos destas correntes, considera que uma determinada sociedade é justa se a sua vida essencial é vivida de uma forma fiel às compreensões partilhadas dos seus membros, e que, portanto, qualquer explicação da justiça distributiva deve ser entendida como uma explicação local.

Propõe-nos, então, este autor uma teoria pluralista da justiça social cuja meta é realizar a "igualdade complexa" compreendida como aquela que respeita a liberdade e que exige a distribuição dos diferentes bens sociais segundo uma diversidade de procedimentos e critérios, ou seja, de acordo com o significado do bem social em causa. De um modo que não deixa dúvidas, afirma que

os princípios de justiça são, eles próprios, pluralistas na sua forma; que os vários bens sociais devem ser distribuídos com base em motivos diferentes, segundo processos diferentes e por diversos agentes; e que todas estas diferenças derivam de diferentes concepções dos próprios bens sociais - consequência inevitável do particularismo histórico e cultural (Walzer, 1999: 23),

não havendo, por isso, sentidos pré-fixados ou ideais, prévios às comunidades e independentes das vicissitudes históricas. Noutro passo, esclarece que

nunca houve um critério único nem um conjunto único de critérios interligados, para todas as distribuições. Merecimento, aptidão, nascimento e linhagem, amizade, necessidade, livre troca, lealdade política, decisão democrática, todos ocuparam os seus lugares, juntamente com muitos outros, numa coexistência incómoda, invocados por grupos concorrentes, confundidos uns com os outros. (ibid.: 22)

Torna-se então claro que, para Walzer, o carácter universal e único da justiça distributiva não tem razão de ser, uma vez que os homens são, em primeiro lugar, activos na criação de sentidos sociais que são distribuídos de acordo com esses sentidos e, depois, porque os critérios de distribuição (e o seu carácter apropriado) são internos a cada esfera distributiva. Ora, é 
precisamente por apelar a esta pluralidade de princípios distributivos que governam a distribuição dos bens que o autor propõe a compreensão da justiça como complexa.

Assim sendo, compreende-se também a sua insistência na defesa do princípio da separação das diferentes esferas sociais (que o próprio Estado deve respeitar), uma vez que, a não verificar-se tal separação, a posição dominante detida numa esfera social pode contaminar a posição noutras esferas, dando deste modo acesso privilegiado a outros bens ou dando vantagens na aquisição desses mesmos bens. ${ }^{1}$ É por isso que se torna pertinente, insiste o autor, entender a justiça como "igualdade complexa", porque ela não diz apenas respeito à igualização em termos de propriedade mas impede ou substitui a tirania social pela qual um grupo utiliza o seu monopólio de um bem para controlar o acesso a outros bens ou para transformar o seu sentido social. ${ }^{2}$

De algum modo, então, a noção de justiça como "igualdade complexa" pode ser entendida, na interpretação de Miller (1995: 3), como "uma ideia de cidadania igual", podendo constituir-se numa base importante para um programa de reforço da democratização da sociedade, uma vez que quanto mais esferas de justiça tiver uma sociedade melhor será do ponto de vista da igualdade complexa porque quanto mais bens sociais houver menos existirá a probabilidade de os indivíduos poderem ser "ordenados socialmente na base da sua performance numa esfera apenas" (ibid.: 223).

Ora, não obstante as potencialidades teóricas da proposta de Walzer, ela não tem ficado imune a variadíssimas críticas. Assim, Joseph Carens, por exemplo, considera que Walzer

pretende que a justiça é o que as pessoas de uma determinada comunidade pensam que seja. Mais exactamente, ele defende que quando os bens são distribuídos de acordo com o sentido que as pessoas numa comunidade atribuem a esses bens então os bens são distribuídos justamente. (Carens, 1995: 49)

\footnotetext{
${ }^{1}$ Do mesmo modo, é denunciada a dominação ilegítima que começa quando um dos princípios distributivos (o de mercado, por exemplo) pretende impor-se aos outros e organizar a distribuição da totalidade dos bens na totalidade das esferas. Walzer (1999: 24-25) está consciente ainda de que, numa sociedade capitalista, "o capital é dominante e rapidamente convertível em prestígio e poder”, papel que numa tecnocracia é desempenhado pelo conhecimento técnico.

${ }^{2}$ Para Walzer (ibid.: 28), a igualdade simples exigiria do Estado uma acção contínua para restringir todo o monopólio ou reprimir novas formas de predomínio, mas que, ao mesmo tempo, levaria determinados grupos a monopolizarem e usarem o Estado para consolidarem o seu próprio controlo sobre outros bens sociais. Refira-se que igualdade simples tem a ver com a livre troca com base em partes proporcionais iguais. Como parece ser nítido, ainda, a igualdade complexa não tem a ver com uma identidade de posse, mas com uma complexa relação entre pessoas mediada por uma série de bens sociais, o que vai exigir uma diversidade de critérios distributivos.
} 
Todavia, acrescenta o autor, o mundo das nossas compreensões (da comunidade moral partilhada), dos nossos sentidos partilhados, ultrapassa as fronteiras de uma comunidade política particular a que nós pertencemos, para além de algumas versões locais da justiça poderem ser incompatíveis com os próprios direitos das pessoas.

De modo semelhante se pronuncia Jon Elster (1995) quando refere que, se há diversidade de concepções de justiça, esta também existe no interior da mesma comunidade e até na própria pessoa colocada em circunstâncias diferentes. Além disso, a concordância quanto ao sentido do bem numa comunidade concreta pode não ser suficiente para justificar um modo particular de distribuição (dispensar cuidados médicos através de mecanismos de mercado, por exemplo) e também porque há certos valores e considerações morais que atravessam as esferas distributivas e influenciam o modo como pensamos acerca da distribuição dos bens. Como o autor pertinentemente acrescenta, os princípios distributivos que governam cada uma das esferas não podem ser determinados independentemente do que acontece nas outras esferas e daí que, por exemplo, qualquer tentativa para melhorar as oportunidades de vida dos mais desfavorecidos, em caso de conflito moral, deve, para ser efectiva, recorrer a várias esferas de justiça (Elster, 1995: 108 e 111). Talvez a justiça, então, sobretudo num contexto de uma sociedade injusta, seja mais inter-esférica do que a igualdade complexa leva a supor.

Finalmente, a ideia de visão social de bens não parece muito compatível com esferas separadas e, neste sentido, Touraine (1996: 51) pensa que a autonomia dos sectores sociais (correspondendo a cada um deles um bem dominante) não é, em democracia, muito justificável, dado que esta se define "não pela separação dos poderes, mas pela natureza dos elos entre sociedade civil, sociedade política e Estado".

Para além de Walzer, também os autores franceses Boltanski e Thévenot (1991) nos falam do mesmo pluralismo a partir das estratégias de justificação concretizadas pelos actores sociais nas situações de litígio. Para eles, a vida social consiste fundamentalmente em organizar compromissos entre os vários mundos ou grandezas que aí se constituem e que corporizam formas de bem comum. E, nesta sequência, distinguem os mundos da inspiração, mercantil, cívico, industrial, doméstico e da opinião, cada qual com o seu modo de generalização - que influencia as práticas de justificação dos actores assim como os modos de conhecimento do mundo social e com a sua ordem legítima, isto é, com uma ordem que define relações entre pessoas mas também benefícios, satisfações e sacrifícios específicos, lógicas de denúncia, etc. 
Em termos de justiça, esta pluralidade de mundos força a que a noção de justiça se contextualize e amplie, sendo reportada a vários princípios que devem recobrir diferentes imperativos (técnicos, económicos, sociais, etc.), sem que tal pluralismo ou diversidade equivalha, no entanto, à defesa de qualquer relativismo.

Um outro aspecto a salientar é que cada um dos mundos referidos está numa relação crítica relativamente aos restantes e, tal como Walzer, também os dois autores em causa denunciam a transferência dos pressupostos argumentativos de um mundo para outro como injusta, porque, entre outras razões, ela pode levar à valoração de objectos estranhos ao mundo em causa ou a alterar as grandezas do que é grande ou pequeno em cada um dos mundos. ${ }^{3}$ Daí, então, que em redor das injustiças seja possível mobilizar uma diversidade de argumentações subsidiárias de vários princípios, uma vez que cada mundo aponta para critérios diferentes de justiça (e, inclusive, para valorizações diferentes da própria dimensão temporal e espacial).

E é assim, também, que os próprios princípios de justiça podem surgir como incompatíveis entre si, entrando em concorrência ou conflito. É o caso da "competitividade dos serviços públicos", por exemplo, em que a disputa pode surgir entre a lógica cívica e a lógica mercantil, uma vez que "as partes em presença estão em desacordo sobre o mundo no qual a prova deve ser realizada para ser legítima" (ibid.: 276). ${ }^{4}$ Outro exemplo desta conflitualidade pode ser dado pela competência profissional, em que, do ponto

\footnotetext{
${ }^{3}$ Os diferentes mundos permitem estabelecer repertórios de sujeitos qualificados pelo seu estado de grandeza. E, assim, no mundo cívico a grandeza assenta na solidariedade e o pequeno é aquele que se desvia, que se singulariza, que rompe com a solidariedade: o excluído é o extremo da pequenez. No mundo doméstico, em que a dimensão relacional do laço (doméstico) é a submissão a um princípio de subordinação ancorado na tradição, o excluído é aquele que se liberta destas normas ou não respeita a relação de proximidade. No mundo da opinião, a reputação ou o reconhecimento marcam o acesso a um estado de grande neste mundo: o excluído aqui é sem abrigo. No mundo mercantil, o princípio de coordenação é a concorrência e a forma de grandeza legítima é o dinheiro: os grandes são os ricos, os excluídos são os pobres. Quanto ao mundo industrial, a forma de grandeza tem a ver com a eficácia: o grande é o que detém as qualidades de performance, capacidade, previsibilidade e fiabilidade, ao passo que o pequeno é o improdutivo, o desempregado. Finalmente, no mundo da inspiração, a singularidade é o princípio a ter em conta, e o excluído é o reservado, o espectador. A conclusão do autor é que a exclusão é, na verdade, uma "categoria abstracta" (p. 167) e que, consequentemente, só ganhará sentido na medida em que se considere o mundo concreto, as economias da grandeza, os compromissos específicos, os arranjos particulares, os modos de expressão dos juízos, as formas de evidência, as relações entre os seres.

${ }^{4}$ Quanto ao papel do Estado, Thévenot frisa que o Estado também interfere na realização de certas ordens de grandeza, que se tornam por isso mais legítimas, designadamente a grandeza cívica e a industrial, uma vez que elas suportam o funcionamento do Estado. Esta ideia é contrária à de Walzer uma vez que este defende, como vimos, que o Estado deve ser o garante das fronteiras entre as esferas de justiça.
} 
de vista do mundo da inspiração, ela pode ser vista como uma operação incontrolável de criação; do ponto de vista doméstico, como levando à perda do sentido do companheirismo; do ponto de vista mercantil, como comportando custos exagerados; do ponto de vista cívico, como uma forma de consolidar a tecnocracia.

Não obstante a complexidade e incompatibilidade das situações e dos modos de avaliação legítimos em que repousam as sociedades complexas e que tornam difícil a concordância sobre a natureza de uma dada situação concreta, tal não impede que se reclame dos actores que eles "passem de uma forma de justificação a outra, ajustando-se à situação" (Thévenot, 1992: 226), que estabeleçam compromissos que, embora frágeis, justifiquem e possibilitem a acção concreta, nomeadamente no interior das organizações.

Finalmente, uma outra perspectiva similar em vários aspectos às duas referidas anteriormente é formulada, entre nós, por Boaventura de Sousa Santos (2000), quando nos propõe a distinção de espaços estruturais de relações sociais, incluindo aí o espaço doméstico, o da produção, o do mercado, o da comunidade, o da cidadania e o mundial.

Cremos, com efeito, que estes espaços, na medida que se estruturam em bases diferentes, podem reportar-se a conceitos de justiça não coincidentes, levando a privilegiar, designadamente, aquilo a que o autor chama "tópicas de emancipação" específicas. De facto, e não obstante a estruturação dominante de cada espaço implicar relações de subordinação, é também possível proceder a tópicas mais consentâneas com o sentido libertador substituindo, por exemplo, no espaço doméstico, uma tópica patriarcal por uma tópica da libertação da mulher; no espaço da produção, substituindo uma tópica capitalista por uma tópica eco-socialista; no espaço do mercado, substituindo uma tópica do consumismo feiticista por uma tópica de necessidades fundamentais e satisfações genuínas; no espaço da comunidade, substituindo uma tópica chauvinista por uma tópica cosmopolita; no espaço da cidadania, substituindo uma tópica democrática fraca por uma tópica democrática forte; no espaço mundial, substituindo uma tópica do Norte por uma tópica do Sul (ibid.: 103-104).

Acrescenta, depois, o autor que haverá senso comum emancipatório "quando os topoi emancipatórios desenvolvidos numa dada comunidade interpretativa encontrarem tradução adequada nos topoi de outras comunidades e se converterem, assim, em topoi gerais" (ibid.: 104).

Este último aspecto, aplicado à nossa problemática, chama, por um lado, a atenção para a existência de diferentes justiças e, por outro, para o facto de estas deverem orientar-se num sentido mais amplo de uma justiça eman- 
cipatória; além disso, parece resultar daqui a defesa da invasão ou da expansão do domínio da justiça através dos seus diferentes sentidos nos espaços estruturais referidos (ideia que não coincide exactamente com as duas propostas teóricas anteriores).

Esta ideia de contaminação ou de combinação é congruente, aliás, com o pressuposto de que os espaços estruturais operam sempre em constelações, de modo que cada dimensão de um espaço está presente em qualquer outra das dimensões correspondentes de qualquer um dos outros espaços estruturais. Daí, então que

[c]omo os espaços estruturais só funcionam em constelações, as acções sociais são muitas vezes informadas por lógicas diferentes e mutuamente incompatíveis, o que significa que cada dinâmica de desenvolvimento, considerada isoladamente, é sempre parcial. (Santos, 2000: 263)

A título exemplificativo deste aspecto, e a propósito da vida sócio-jurídica, o autor refere que, na prática, ela envolve sempre "interlegalidade", podendo a regulamentação/desregulamentação ao nível do direito estatal ser neutralizada ou compensada por aumento de regulamentação/desregulamentaçao ao nível de outras escolas de direito (do direito local de produção ou do direito global das transacções internacionais, por exemplo).

E é assim que vivendo "num tempo de porosidades e, portanto, também de porosidade ética e jurídica", vivenciamos também "um direito poroso constituído por múltiplas redes de ordens jurídicas que nos forçam a constantes transições e transgressões" (ibid.: 205). É neste sentido que, no que ao direito diz respeito, o carácter jurídico das relações sociais "não decorre de uma única forma de direito, nomeadamente do direito do espaço de cidadania (o direito estatal), mas sim das diversas constelações entre diferentes formas de direito" (ibid.: 301), de constelações de juridicidade ou juridicidades, de "formas de direito diferentes, combinando-se de modo diferente de acordo com o campo social específico a que fornecem a ordenação normativa" (ibid.: 270). Isto significa então, e entre outros aspectos, que, num determinado momento, coexistam vários direitos (doméstico, da produção, de troca, da comunidade, estatal e sistémico).

A ser correcta esta nossa interpretação, pensamos ser possível distinguir também concepções diferentes de justiça e de modos de ver práticas de desigualdade e de exclusão, para além de modos de pensar, organizar e de impor determinadas concepções/representações de direitos que podem reforçar, colidir, acomodar, omitir, resistir ou entrar em cumplicidade com outras justiças de outros espaços estruturais. 
É por isso que faz sentido falarmos também, aproveitando a sugestão de Boaventura de Sousa Santos, numa justiça doméstica ou familiarista, numa justiça empresarial ou produtivista, numa justiça de troca ou mercantil, numa justiça comunitarista, numa justiça estatal ou oficial e numa justiça sistémica ou mundial, embora deva reconhecer-se que a justiça veiculada pelo direito estatal seja a dominante, porque, segundo o autor (ibid.: 278), este se apresenta como "um poder cósmico, altamente organizado e especializado, movido por uma pretensão de monopólio e comandando vastos recursos em todos os componentes estruturais do direito (violência, burocracia e retórica)", funcionando, portanto, como um referencial das restantes.

Em sintonia com a plurivocidade do discurso da justiça que, sobretudo nos tempos actuais, parece estar a transformar-se, na verdade, num discurso de justiça complexa, num "discurso de gramáticas múltiplas e também conflituais” (Hogan, 1997: 29), que jogam com definições várias e até com "dialectos locais e populares de justiça", fazendo todos parte de uma luta tendo em vista a fixação de uma certa ordem social e a construção do sentido da cidadania num momento determinado, encontramos ainda outros autores teoricamente enquadráveis numa visão mais contextualizada ou relativizada da justiça.

Pelo impacto da sua obra e sobretudo pela contestação à perspectiva universalista de justiça e à concepção de democracia deliberativa de Habermas, cabe destacar aqui também o pensamento de Iris Young (1990). Esta autora começa por criticar o paradigma distributivo porque este, para além de reduzir a justiça a uma distribuição igual de direitos como se estes fossem simples bens materiais que se possuem e se distribuem, impõe uma norma igualitária que coage a diferença a tornar-se uniformidade; ou seja, esse paradigma tende a impor uma falsa identidade sob uma norma igualitária, o que faz com que as identidades individuais não compatíveis ou inconsistentes com esta norma sejam silenciadas, impedindo assim a contestação às concepções dominantes (nomeadamente de personalidade e de bem-estar).

É nesta sequência que as teorias contratualistas liberais são criticadas porque a noção universalista de justiça que lhes subjaz se torna insensível à pluralidade de práticas conferidoras de identidade e porque, em nome do mesmo paradigma distributivo de bens, elas esquecem frequentemente a (in)justiça cultural e questões tão concretas como a "soberania" da mulher, dos homossexuais e pessoas de cor, por exemplo, o que vai exigir, desde logo, a reforma dos fóruns legais ou legislativos de modo a que a deliberação não fique determinada pela riqueza, a masculinidade ou por aspectos dominantes de cultura e raça que estão normalmente sobre-representados 
nesses mesmos fóruns. ${ }^{5}$ Isto significa, ainda de acordo com Young, que as normas deliberativas de Habermas tendem, afinal, a ser culturalmente específicas e acabam por operar como formas de poder que desvalorizam ou silenciam outros discursos (Cunningham, 2002: 182). A mesma crítica deve ser dirigida, acrescenta a autora, à noção de esfera pública como lugar de bem comum, dado que esta é frequentemente definida de um modo que vai contra os interesses dos grupos subordinados ou marginalizados.

Young propõe então a contextualização, não da distribuição (e das políticas de despolitização que implica), mas dos conceitos de dominação (interpretada como fenómeno estrutural ou sistémico que exclui as pessoas de participarem na determinação das suas acções ou na formulação das condições dessas mesmas acções) e de opressão (que tem a ver com constrangimentos institucionais ao desenvolvimento e à aprendizagem), ${ }^{6}$ ao nível dos processos de tomada de decisão, da divisão do trabalho e da cultura.

Precisando mais um pouco o seu conceito multidimensional de justiça, Young afirma que ele se prende com a "eliminação da dominação e da opressão institucionalizadas" (ibid.: 15), entendendo por contexto institucional aquele que inclui estruturas e práticas, regras e normas, linguagem e símbolos, que medeiam as interacções sociais em instituições do Estado, na família, na sociedade civil bem como no local de trabalho. Na verdade, a justiça social diz respeito sobretudo às condições institucionais e não às preferências e modos de vida das pessoas ou grupos. Consequentemente, avaliar a justiça social de acordo com o ter oportunidades deve envolver a análise, não de um resultado distributivo, mas de uma estrutura social, na medida em que ela capacita ou constrange os indivíduos em situações rele-

\footnotetext{
5 Young assume também as ferramentas da desconstrução contra os ideais da comunidade que geram dicotomias, marginalizações ou exclusões. Mas distancia-se, por exemplo, de Derrida porque pensa ser possível colocar "conceptualizações alternativas" à ideia de que a "desconstrução é justiça”". O primeiro passo aqui é considerar que os indivíduos sejam compreendidos como "heterogéneos e descentrados". Propõe ainda uma série de conceitos e condições relevantes para uma concepção contemporânea de justiça social, as quais desenvolve nas "cinco faces da opressão".

${ }^{6}$ As cinco faces da opressão são: a exploração, a marginalização, o imperialismo cultural, a violência e a pobreza. E aqui podemos considerar que a experiência da injustiça também é heterogénea, pois alguém que seja tratado injustamente no local de trabalho pode, ele próprio, actuar opressivamente na esfera doméstica, por exemplo. Então, para acabar com a opressão e promover uma autêntica democracia participativa não basta o reconhecimento dos direitos individuais a partir da perspectiva universalista. Fazem falta, além disso, medidas específicas a favor das reclamações diferenciadas dos grupos oprimidos, quer no terreno legal, quer no terreno da acção política, pondo na mão destes grupos meios institucionais e fundos públicos para conseguir a "representação e o reconhecimento efectivos". É este o sentido da "cidadania diferenciada", que entretanto outros autores criticam porque viola os princípios liberais como a igualdade entre cidadãos e a neutralidade do Estado, para além de introduzir a arbitrariedade (pois não é fácil determinar quem merece tratamento diferenciado) e, finalmente, porque debilita a função integradora da cidadania (Ledesma, 2000).
} 
vantes. As consequências visíveis desta posição ao nível, por exemplo, da interpretação do princípio da igualdade de oportunidades em educação, leva a considerá-lo, não tanto como algo que é possível dar mais ou menos (em sentido distributivo), mas antes como algo que deve estar em sintonia com a interpretação da educação como sendo "primariamente um processo que tem lugar num complexo contexto de relações sociais" (ibid:: 26).

Em síntese, a concepção multidimensional de justiça defendida pela autora leva-a de facto a denunciar as limitações da conceptualização liberal (e também da conceptualização pós-moderna assente na compreensão da justiça como reconhecimento), propondo uma noção política e estrutural mais abrangente de justiça, ao defini-la como libertação das relações de opressão, nomeadamente das relações que decorrem do imperialismo cultural (Gewirtz, 1998: 477).

Por fim, há que salientar que Young, embora estando interessada numa política valorizadora da diferença, está simultaneamente consciente de que a afirmação da diferença pode levar a reinstalar estigmas e exclusões. Daí afirmar:

Um pluralismo cultural democrático exige, assim, um sistema dual de direitos: um sistema geral de direitos que são os mesmos para todos e um sistema mais específico de políticas e direitos que tomem em conta a especificidade de cada grupo. (Young, 1990: 174)

Esta solução leva-nos ainda a afirmar que, apesar de tudo, a autora reinsere a universalidade na sua teorização da justiça, embora agora numa relação dialéctica com a particularidade, a posicionalidade e a diferença grupal.

\section{Justiça complexa e educação}

O conceito de justiça articula-se em qualquer democracia com outros conceitos, como o de igualdade, de equidade, de liberdade, de mérito, de poder e autoridade, que vão condicionar também o modo como pensamos a educação e o modo como as escolas devem organizar-se para cumprirem as suas finalidades. Na verdade, tal como é inseparável do conceito de democracia, o conceito de justiça é também inseparável do de educação, de tal modo que Sturman (1997: 124) considera mesmo que "no contexto escolar, a justiça social não é algo diferente de educação" .

\footnotetext{
${ }^{7}$ As políticas de justiça social têm-se baseado normalmente nos princípios da justiça distributiva, que visam sobretudo, no caso da educação, "igualizar - através dos indivíduos, das escolas ou de grupos sociais - o acesso à educação, aos recursos educativos e aos benefícios esperados da educação" (Sturman, 1997: 115).
} 
Apesar desta íntima articulação entre justiça e educação, não deixa de ser surpreendente que aquela tenha surgido, mesmo nas análises mais orientadas para as políticas educativas, como um conceito subteorizado (Gewirtz, 1998: 469), não tendo sido, aliás, o primeiro conceito a impor-se no campo educativo. Nos casos concretos em que tem sido explicitamente invocada, a justiça na educação tende a ser relacionada fundamentalmente com o princípio da igualdade de oportunidades, com o mérito, com o respeito, com a igualização de condições e até, mais recentemente, com a eficiência, a qualidade e a competição; ou seja, a justiça tende a aparecer em educação mediada por outros conceitos, mormente pelo de "igualdade de oportunidades", independentemente das críticas de que este tem sido alvo quando erigido como o único princípio das políticas educativas (Burbules e Lord, 1981). ${ }^{8}$

Não obstante esta dispersão, Gewirtz (1998: 472) considera que as noções dominantes da justiça distributiva no campo da educação podem resumir-se ora à definição liberal fraca de justiça como igualdade de oportunidades (estando esta dependente da existência de direitos formais iguais, igualdade de acesso e igualdade de participação) ora ao sentido liberal forte e radical como igualdade de resultados "que procura assegurar taxas iguais de sucesso para diferentes grupos na sociedade através de uma intervenção directa para superar desvantagens". Apesar da sua amplitude, ambas as versões, acrescenta a autora, tendem a não dar a devida ênfase aos problemas relacionadas, por exemplo, com a riqueza, com as hierarquias de poder ou com outros privilégios.

No sentido de superar estas limitações de uma conceptualização liberal de igualdade, a mesma autora recorre, a propósito, à sugestão de Lynch (1995), que propõe a compreensão da igualdade como "igualdade de condição", a qual envolveria

o desenvolvimento de uma sociedade igualitária que se empenhasse na igualdade de condições de vida de todos os membros da sociedade (cidadãos ou não cidadãos), tomando na devida conta a heterogeneidade deles resultante da diferença sexual,

\footnotetext{
${ }^{8}$ É que, perante a situação actual, é necessária a consideração de que o princípio singular da igualdade de oportunidades tende, na verdade, a ser restritivo, desde logo porque acentua que a função da escola é fornecer oportunidades e não satisfações, aberturas limitadas e não direitos inalienáveis, para além de devolver a responsabilidade àqueles que assumem essas mesmas oportunidades (Davies, 1990: 180). Mais, este mesmo princípio passa a equivaler, num contexto em que a prevalência da lógica de mercado era evidente, a um meio para deformar o próprio princípio da igualdade educativa, uma vez que ele acaba objectivamente por funcionar como um mecanismo para aceder a posições desiguais da sociedade, tornando-se assim numa forma mais de legitimar as desigualdades (Flecha, 1994: 78).
} 
etnicidade, deficiência, religião, idade, orientação sexual ou de qualquer outro atributo. Essa sociedade não se preocuparia apenas com a igualização da posição (acesso, participação e resultados) de grupos marginalizados em cada um dos níveis das hierarquias de riqueza, poder e privilégio. Mais do que isso, ela implicaria a igualização da riqueza, do poder e dos privilégios. (Lynch, 1995, apud Gewirtz, 1998: 472)

Seria, aliás, esta conceptualização, acrescenta Gewirtz, que seria complementada e ampliada pela formulação de Young quando definiu a justiça, como vimos, como libertação das relações de opressão.

Depois deste excurso pela questão da justiça e da igualdade na educação, convém retomar agora a questão das implicações da justiça complexa ao nível da educação e mais particularmente ao nível das organizações educativas.

Um dos primeiros aspectos a salientar é que, ultimamente, alguns investigadores, influenciados pelo pensamento de autores referidos anteriormente, vêm interpretando o espaço escolar como uma arena de intersecção de vários princípios de justiça, nem sempre coincidentes, cada qual invocando uma determinada concepção de bem e veiculando uma dada interpretação de justiça. Nesse sentido, a escola emerge como um "lugar de vários mundos" (Derouet, 2000), o que de algum modo é congruente com a visualização plurifocalizada da sua realidade, designadamente quando é realçado o carácter complexo, "políptico e multidiscursivo" (Estêvão, 1998) dessa realidade, perpassada por pressões institucionais múltiplas que a condicionam não só nas suas finalidades e funções, mas também nos seus vectores emancipatórios e reguladores e nos seus princípios argumentativos.

Isto é, a escola, do ponto de vista organizacional, é essencialmente uma organização plural, com uma vida social mobilizada em torno de compromissos entre os vários mundos que aí se constituem, com estratégias múltiplas de justificação concretizadas pelos actores sociais escolares, designadamente nas situações de litígio (Estêvão, 2001). Isto vai implicar então o reconhecimento de que no interior da escola se mobilizam justiças e argumentações subsidiárias de princípios diferentes, uma vez que cada mundo aponta, de facto, para gramáticas diferentes de justiça e para ordens de grandeza também distintas.

Esta teorização baseada em mundos diferentes pode ajudar a compreender, entre outros aspectos, a variação que ocorre na escola ao nível da justificação das políticas, uma vez que, como nos diz Thévenot (1992), estas podem invocar, como no exemplo da valorização do local ou da construção $\mathrm{da}$ autonomia da escola, ora a ordem mercantil em nome do imperativo da concorrência, ora a ordem cívica regulada pelo imperativo da solidarie- 
dade, do interesse geral e da cidadania, ora a ordem industrial pela invocação da eficácia, ora a ordem doméstica regida pelo imperativo do amor à criança, da confiança e da proximidade.

Independentemente de outras consequências que possam advir para a compreensão da ordem interna escolar, estes diferentes modelos referenciais pressupõem, desde logo, que a coesão social e as dinâmicas de transformação e mudança no interior da escola podem confrontar-se com dificuldades que decorrem naturalmente da pluralidade de princípios que a perpassam e que exigem um investimento claro na construção política de acordos ou de compromissos (eventualmente sobredeterminados por princípios de um mundo ou pela articulação de princípios de vários mundos) para que ela funcione. Por outro lado, cada um dos princípios (doméstico, industrial, de mercado...) com os seus modelos (comunitário, eficácia, concorrencial...) tende a estar no interior da escola em tensão nomeadamente com o princípio cívico, procurando cada um deles instaurar a diferença e, também, as suas desigualdades.

Para se compreender melhor este ponto de vista, Derouet (1992: 33) apresenta as várias definições de escola que se foram constituindo ao longo dos tempos assim como o seu princípio de justiça prevalecente (ainda que nem sempre explicitado). E é assim que, nas décadas de 50 e 60, a questão da justiça (formal) se baseava fundamentalmente no princípio da igualdade de oportunidades - que passou a ser "o princípio regulador do mundo escolar" - oferecendo uma estandardização de condições propiciadoras da revelação de cada um de acordo com o mérito ao mesmo tempo que legitimava a política de centralização do Estado. Nessa altura, a equidade da distribuição é julgada pela medida de um princípio de justiça particular, que é o da verificação de que "a selecção opera bem em função apenas do mérito individual" (Meuret, 1999a: 7-8). Ou seja, a justiça do processo de selecção tinha a ver com a verificação de que se havia seleccionado de acordo com os méritos dos alunos.

Mais tarde, a partir de 70 sobretudo, este princípio cívico da igualdade de oportunidades começou a sofrer a concorrência de outros princípios de acção, designadamente do princípio da cultura crítica, do princípio comunitário e do princípio de mercado, em que as referências da justiça passam a ser as relacionadas com a comunidade, com a empresa, com a eficácia, com o mercado, assim se quebrando o mundo relativamente coerente da escola assente no princípio cívico.

Nesta última fase, entrar-se-ia de facto num universo de "justificação múltipla", com vários princípios reportados a concepções de justiça plurais que dariam razões específicas às diferentes políticas educativas e, designa- 
damente, às proposições mais concretas de descentralização e de autonomia escolar (Estêvão, 2002), cabendo ao princípio cívico uma função sobretudo de regulação.

Entretanto, também as condições do debate sobre a justiça evoluíram (a par de outras evoluções, como a do estatuto social do saber ou as próprias condições políticas do debate sobre a justiça), designadamente pela denúncia de outras desigualdades através de determinadas ideologias (como a da qualidade) e pela sua aplicação a outras categorias (rapazes-raparigas, nacionais/emigrantes, por exemplo). Daí que se verifique não apenas uma "extensão do campo da questão da justiça", mas também "uma transformação desta questão na medida em que, num leque tornado mais aberto, é necessário justificar o interesse por uma dada desigualdade em vez de uma outra qualquer" (Meuret, 1999a: 8).

Com efeito, a questão da justiça adquire nesta altura uma outra importância e um outro conteúdo, agora mais ligados à igualdade de condições de ensino, à correspondência dos conteúdos de que cada um terá necessidade ao longo da vida, à aquisição de um nível mínimo de competências. Por outro lado, hoje exige-se também que se demonstre quais as desigualdades que são injustas e que a argumentação contra as injustiças comine as desigualdades com os princípios de justiça que aparecem nas diversas teorias deontológicas. ${ }^{9}$

Esta problematização leva-nos ainda a convocar aqui, ainda que sumariamente, o pensamento de Bourdieu, quando analisa as funções de reprodução e de legitimação das desigualdades sociais que a escola cumpre, nomeadamente pela transmissão de uma cultura imposta como legítima, isto é, portadora de um discurso socialmente neutro, universal e não arbitrário, indiferente à distribuição do poder na sociedade. Por outras palavras, a cultura escolar como cultura dominante dissimulada trata formalmente de modo igual, em direitos e deveres, quem é diferente, exigindo dos alunos qualidades que são desigualmente distribuídas entre as classes sociais, designadamente o capital cultural e o relacionamento com a cultura e o saber (Bourdieu, 1998). Então, a relação de comunicação pedagógica é para este autor "uma relação formalmente igualitária, que reproduz e legitima, no entanto, desigualdades anteriores" (Nogueira e Nogueira, 2002: 29), por um processo que Bourdieu e Passeron $(\mathrm{s} / \mathrm{d})$ haviam caracterizado já como "violência simbólica". Torna-se claro, portanto, que a justiça ou a equidade

\footnotetext{
9 O argumento da "assimetria operacional", que anuncia que é justo dar mais poderes e recursos aos que farão deles melhor uso, porque as suas competências e capacidades são superiores, pode ser um exemplo destas teorias (ver Meuret, 1999b: 109). Sobre as "novas" desigualdades, que frequentemente não se reduzem "nem ao berço nem à posição de classe", ver Dubet (2001).
} 
formal e universal que a escola apregoa reproduzem de facto, embora de forma velada, uma pluralidade de formas de injustiça, situação que se agrava na medida em que a escola possibilita a acumulação e convertibilidade das diferentes formas de capital (nomeadamente pela conversão do capital socioeconómico em capital cultural sob a bandeira do mérito).

Por conseguinte, este reconhecimento da pluralidade de formas de capital, do seu funcionamento e das implicações em termos de desigualdades na escola reforça, do nosso ponto de vista, a problematização da justiça como complexa, possibilitando-nos falar, na verdade, em novas formas ou configurações de justiça, as quais variam no seu poder de harmonização, atracção ou resistência relativamente à juridicidade dominante, desde logo porque a posse e distribuição dos diferentes capitais, assim como os critérios distributivos para que remetem, são diferentemente valorizados pelos habitus da escola e da justiça escolar.

Em síntese, considerando que as desigualdades no mundo de hoje são múltiplas e decorrentes de relações de classe específicas que se estabelecem em vários mundos, ${ }^{10}$ haverá que contar então com registos de dominação (e, acrescentaríamos, de justiça) não homogéneos, ideia que a teoria dos capitais de Bourdieu acaba por corroborar ao distinguir várias espécies de capital, ou seja, vários poderes que definem as probabilidades de ganho num campo determinado (neste caso, na educação) e que contribuem para determinar depois a posição no espaço social (Bourdieu, 1989: 134).

Se tivermos em conta, ainda, o pensamento deste autor e a nossa compreensão da escola como lugar de vários mundos, pensamos ser possível ampliar ou, pelo menos, matizar, a análise do alcance do poder dissimulador e legitimador da escola enquanto instituição social, na medida em que se mobilizam vários princípios de justiça e de igualdade. Assim, e a título de exemplo, o critério distributivo do mérito, muito vinculado ao capital cultural escolar, pode ser mais facilmente justificado, ou dissimulado, quando se reconhece a existência na escola da lógica do mundo industrial que tende a subalternizar outros mundos ou outras justificações mais congruentes com as desigualdades de classe. Do mesmo modo, se aceitarmos que o mundo da inspiração de Boltanski e Thévenot estrutura também a escola, não haverá dúvidas de que o seu critério de justiça irá sublinhar a relação ao saber, à arte e à cultura, estabelecendo quem é "grande" ou quem é "pequeno" justamente neste mundo, desde logo pelos critérios de originalidade, elegância, subtileza, deixando na penumbra outros referenciais

\footnotetext{
${ }^{10}$ Dubet (2001: 10) distingue, a este propósito, o mundo dos "competitivos", o mundo dos "protegidos", o mundo dos "precários" e o mundo dos "excluídos".
} 
mais claramente classistas. Ainda um outro exemplo: se o mundo doméstico da escola mobiliza o critério da intimidade, da interdependência ou da proximidade, a posse de um babitus familiar mais consentâneo com o capital cultural escolar contribuirá, designadamente pelo desenvolvimento de estratégias individuais ou colectivas, para definir igualmente quem é grande na escola, ao mesmo tempo que reforça o sentido da justiça e da justeza dos seus merecimentos.

Independentemente de outras consequências, esta perspectivação da escola dá, por um lado, um cariz contingente à sua ordem interna e à cultura escolar e, por outro, realça a disputa entre vários arbitrários e a relação de forças entre os diversos agentes tendo em vista a construção de uma ordem interna legítima. Além disso, a predisposição para actuar dentro de um determinado sentido ou de acordo com um determinado modelo de referência no seio da escola deve ser articulada com as próprias disposições incorporadas pelos sujeitos no seu processo de socialização, donde se infere que os agentes que incorporem, nomeadamente pela bagagem herdada na família, o capital cultural mais ajustável ao tipo de "convenções" (no sentido de Boltanski e Thévenot) que a escola privilegia, tenderão naturalmente a ver o seu poder reforçado e a ser mais bem sucedidos. Consequentemente, as estratégias de acção no interior da escola têm muito a ver com o volume e os tipos de capitais (económico, social, cultural, simbólico...) que são diferentemente valorizados consoante o predomínio dos mundos que estruturam a escola e dos seus princípios específicos de justiça.

Não obstante estes desenvolvimentos do pensamento de Bourdieu, estamos convictos da dificuldade de transpor para a nossa análise algumas das abordagens do autor. E uma das razões prende-se com a sua perspectiva macrossociológica que coloca como fundamental a relação entre o sistema de ensino e a estrutura social ou, de modo mais preciso, a correlação entre as desigualdades sociais, sobretudo culturais, e as desigualdades internas ao sistema educativo, não atendendo devidamente ao modo específico como a escola intervém no processo de reprodução social (embora fale na auto-reprodução da escola pela padronização de um modelo escolar, com os seus próprios códigos) nem ao facto de a forma escolar não ser "propriedade exclusiva de um grupo social" (Dubet e Martuccelli, 1996: 314). Talvez para sermos mais fiéis ao seu pensamento, devêssemos tentar ver de um modo mais explícito a escola como lugar de vários mundos, mas sobredeterminados, eles também, pelas relações de classe, onde, inevitavelmente, os problemas de justiça/injustiça se colocariam como faces das mesmas desigualdades sociais e culturais mais amplas, perpassando por todos os seus mundos. 
Uma outra implicação da nossa teorização da justiça complexa na escola verifica-se de modo visível a nível curricular. É sabido que a organização educativa tem manipulado sobretudo a supremacia da justiça distributiva singularmente concebida, ou seja, vista como tratando a educação como a justiça económica trata o dinheiro ou como se as pessoas fossem possuidoras e consumidoras do bem educativo, distribuindo as mesmas quantidades de educação ou de currículo (hegemónico), independentemente de tal procedimento produzir ou não o mesmo efeito quando aplicado a alunos diferentes. Daí, então, que Connell (1995: 32) proponha outro conceito de justiça, neste caso a "justiça curricular", que diz respeito "aos modos pelos quais o currículo concede e retira o poder, autoriza e desautoriza, reconhece e desconhece diferentes grupos de pessoas e seus conhecimentos e identidades" (cf. também Connell, 1997).

Para além de outras vantagens, tal perspectiva levaria a considerar mais seriamente também a "posição não-sincrónica" de que falava McCarthy (1988), em que se analisam áreas de diferença de umas categorias (classe, etnia, diferença sexual, raça) em relação a outras, no pressuposto de que as dinâmicas de discriminação nem sempre actuam de um modo simétrico. Isto implica que estas áreas de diferença podem conflituar no interior da escola, designadamente nas questões relacionadas com o currículo, o ensino, a cultura escolar, como também nas áreas de administração aquando, por exemplo, dos debates sobre poder, autoridade e empowerment (Parker e Shapiro, 1993: 38), uma vez que aí se podem confrontar posições não-sincrónicas problemáticas dos diferentes actores.

Assim sendo, e por mais importante que seja o conceito de classe social para o estudo da diversidade/diferença em educação, haverá que analisar as complexas interacções entre a classe e outras características como a raça, o sexo, a etnia, a orientação sexual, ou então, e a outro nível, a natureza pública ou privada da educação, a localização da escola, entre outras, de modo a construírem-se comunidades não discriminatórias, onde, por um lado, se combata a valorização dos símbolos culturais hegemónicos que levam à "indiferença pelas diferenças" (Bourdieu e Passeron, 1964) ou à sua hierarquização de modo a excluí-las e, por outro, se não reduzam as desigualdades organizacionais, por exemplo, à diferença derridiana, com pouca força política.

Também entre nós, e dentro destas preocupações curriculares, ganha relevância a proposta de Stoer e Cortesão (1999) de uma educação inter/ multicultural, que respeite uma "política da diferença" capaz de garantir a complexidade e a multidimensionalidade entre a estrutura e a cultura e 
que concretize, afinal, a não-sincronia das diferenças relativas à raça, etnia, classe e sexo. Esta educação deve, segundo os autores, assumir-se como parte integrante do "movimento para a solidariedade e justiça social". Ou seja,

proclama-se que um princípio ético e político de justiça social deve orientar não só as práticas pedagógicas dos professores nas escolas, como também a própria selecção do saber para o currículo ao nível da elaboração das políticas educativas. (Stoer e Cortesão, 1999: 46)

Uma outra implicação da concepção de justiça complexa tem sido analisada por outros autores nos planos da própria experiência escolar, das desigualdades de bem-estar na escola (qualidade humana, convivialidade da experiência escolar) e da própria experiência de justiça/injustiça por parte dos alunos.

E a este propósito, sugere Denis Meuret:

Aquilo que se pode saber da experiência que os alunos têm da injustiça é que ela não é somente estruturada pelas desigualdades, mas também pelo arbitrário: arbitrário das notas, da orientação, das sanções, dos exames, das exclusões. O sistema judiciário interno à educação oferece particularmente poucas garantias aos justiciáveis. (Meuret, 1999a: 15)

Portanto, a experiência escolar é um campo de desigualdades, umas mais ligadas à categoria social ou nacional dos alunos, mas outras menos.

Partindo da consideração dos sistemas escolares como realizações práticas de princípios de justiça, Dubet (1999) diz-nos que é possível, desde logo, medir os seus efeitos. Neste sentido, ele distingue nas representações dos alunos, por razões de comodidade, três princípios de justiça concorrentes: o mérito, o respeito e a igualdade, que se combinam de uma forma crescentemente mais complexa desde os níveis primários aos superiores.

Quanto ao mérito, ele é entendido como correspondência entre as contribuições e as retribuições, levando a que

os alunos descrevam a injustiça como uma ruptura de equivalência entre as contribuições, o trabalho fornecido, e as retribuições, as notas obtidas. A injustiça é a ruptura desta equivalência, o arbitrário das notas, o não reconhecimento das performances... É justo o que sanciona as performances de cada um, a conformidade às expectativas dos adultos. (Dubet, 1999: 181) 
Congruentemente, a igualdade consiste em tratar todos os alunos do mesmo modo, pelo que a escola deve tratar cada um da mesma maneira independentemente das suas performances. Aqui, o que é justo é aquilo que reforça a coesão do grupo de alunos, verificando-se então que "a justiça da igualdade é a da 'solidariedade mecânica' e da comunidade" (ibid.: 182).

Relativamente ao respeito, este refere-se à dignidade da pessoa ou a uma norma protegendo os indivíduos da violência do mérito. Aqui, a injustiça corresponde à humilhação do aluno pelo juízo escolar, pelo que o respeito corresponde a uma concepção procedimental da justiça: o que importa não é tanto o mérito ou a igualdade mas o modo com eles são realizados. O bem-estar dos alunos tem, segundo Dubet, sobretudo a ver com este princípio, o qual não tem forçosamente efeitos positivos sobre a igualdade e as performances. Ainda sobre o respeito, o mesmo autor, noutra obra, considera que o respeito se impõe

desde que as desigualdades de mérito e de desempenho não devam afectar a igualdade entre as pessoas. Desse ponto de vista, o desprezo aparece como confusão entre as esferas de justiça, quando as desigualdades de desempenho desqualificam os indivíduos enquanto sujeitos livres e iguais. Por exemplo, os alunos admitem as classificações e as hierarquias escolares, desde que os piores alunos não sejam desprezados nem maltratados e que o julgamento da pessoa e o do desempenho sejam claramente diferenciados. (Dubet, 2001: 18)

Estas três dimensões da justiça são, segundo o autor, autónomas, havendo até uma tensão entre elas e correspondem aos três mundos ou cidades de Boltanski e Thévenot, ao industrial, ao cívico e ao doméstico. No entanto, Dubet vai além desta correspondência porque os três critérios derivam também das dimensões essenciais da experiência escolar:

O mérito inscreve-se na dimensão estratégica e competitiva da experiência escolar, a igualdade procede da integração social e da adesão às normas do grupo, enquanto o respeito procede da subjectivação dos actores, isto é, da formação da sua distanciação e da sua reflexividade como indivíduos "diferentes" dos outros. (Dubet, 1999: 183)

Neste sentido, as três dimensões da justiça "são sobretudo capacidade práticas de ajustamento aos outros e maneiras de construir a vida comum" (ibid.: 183).

Estamos, assim, perante várias esferas de justiça, o que leva ainda o mesmo autor e Martuccelli (1996: 146) a esclarecerem que, por exemplo, o que 
vale na turma não vale no corredor, o que vale para o aluno não vale para a pessoa, o que é grande no domínio escolar pode ser julgado pequeno no universo da adolescência.

Por outro lado, todo o tratamento diferencial que não se apoie num critério de justiça é denunciado pelos alunos como injusto, assim como os alunos denunciam os professores quando estes confundem registos que deviam estar separados (por exemplo, comportamento e desempenho). Mais, "quando a confusão das esferas de justiça atinge o domínio pessoal, as reacções são extremamente vivas" (ibid.: 146). É que, para os alunos, a liberdade confunde-se com a arte de separar domínios de vida, situação que nem sempre os professores respeitam, precisamente porque "uma boa parte da disciplina e da autoridade escolares está assente no controlo dos espaços pessoais dos alunos" (ibid.: 147).

Em síntese, os alunos, que nunca são plenamente cidadãos da sua escola, balançam entre vários princípios de justiça que lhes permitem mobilizar não só a sua capacidade argumentativa, mas também a capacidade de universalização dos seus juízos. Mas o que é curioso é que, ainda segundo o mesmo autor atrás citado, a experiência da injustiça dos alunos se sobrepõe à da justiça, na medida em que é a injustiça que é "vivida" enquanto a justiça é "argumentada". Apesar desta sensibilidade às injustiças, ela não se transforma em crítica organizada e, muito menos, em acção organizada. Para que isto acontecesse, seria necessário que o professor acumulasse condutas injustas em todos os registos de justiça. ${ }^{11}$

Por esta análise, mais uma vez se confirma a pertinência de a justiça ser encarada também na sua pluralidade argumentativa e de operacionalização, uma vez que nos permite compreender um pouco melhor a dinâmica e a especificidade dos processos que ocorrem no interior das organizações educativas assim como o sentido complexo das acções dos actores escolares.

\section{Justiça e experiência ética nas organizações educativas}

A justiça está intimamente ligada à base normativa da educação e ao posicionamento ético no modo como se pensa e actua na escola. Aliás, qualquer debate sobre a escola como organização e sobre arranjos organizacionais mais apropriados não é meramente um debate organizacional; ele é também ético, porque o que está em causa é a prática futura de educação, é a

\footnotetext{
${ }^{11}$ Outro aspecto importante que o autor acrescenta diz respeito ao facto de este sentimento de injustiça ser "necessário" aos alunos, porque ele participa no processo de socialização e na formação da subjectividade dos indivíduos que descobrem, desse modo, a distância entre os princípios e as condutas, gerando assim um espaço de autonomia.
} 
prática de justiça social expressa em normas e em padrões de direitos e obrigações que podem, como é sabido, seguir lógicas diversas e sentidos de moralidade também distintos.

$\mathrm{Na}$ verdade, e tal como a própria democracia enquanto arena de luta política é inseparável da ética, assim qualquer concepção de escolaridade pública e de escola está necessariamente vinculada a um conceito de serviço comprometido com considerações morais e políticas assentes em valores. Consequentemente, o que aqui está em causa é a adesão a determinado conjunto de valores em detrimento de outros; ou seja, e em termos críticos, o problema coloca-se na opção ou não por uma filosofia pública democrática "que dê credibilidade a uma forma emancipatória de cidadania em cuja parte medular se coloquem a igualdade e a vida humana" (Giroux, 1993: 34). Daqui decorre que os educadores têm de fazer opções que podem ir ora num sentido mais controlador e de dominação, ora num sentido mais emancipatório que reforce o protesto contra as práticas ideológicas e sociais da actual sociedade capitalista "que privam a vida pública de um discurso ético crítico" (ibid.: 72).

Pensamos que também aqui a problematização da justiça como complexa pode não só propiciar um maior conhecimento, como vimos, acerca da natureza das organizações educativas e da multi-referencialidade das práticas educativas, mas também permitir aprofundar o sentido da "ética da crítica" e da "ética da justiça", que responda de modo mais concreto às questões, por exemplo, da igualdade, do bem comum, da participação democrática e dos direitos humanos (Starratt, 1991 e 1994). Além disso, a convocação da compreensão da justiça como complexa pode contribuir ora para analisar as agendas das reformas educativas (se obedecem ao critério universalista ou, pelo contrário, a esferas particulares de justiça), ora para orientar as escolas no sentido de ajudarem a dar uma resposta ao paradoxo ético da pós-modernidade (de que fala Bauman, 1992), ou seja, como actuar eticamente num mundo que abandonou a crença nas regras de uma moral universal e cuja resolução pode estar na consideração da "justiça como reconhecimento", na linha de Fraser (1977), ou na "abertura à alteridade não assimilada", de acordo com a proposta de Young (1990). ${ }^{12}$

Se fosse permitido propor então uma agenda de intervenção, a escola (ou qualquer outra organização educativa) devia começar pelas dimensões ligadas a uma "ética da crítica", capaz de questionar, entre outros aspectos, a "paideia funcionalista" (na expressão de Dubet e Martuccelli, 1996), a

\footnotetext{
12 Esta proposta de Young teria ainda o mérito de contribuir para uma espécie de "universalidade imanente" entendida como participação e inclusão de todos numa vida social e moral que não se esconde atrás de afiliações, sentimentos, compromissos ou desejos particulares (ibid.: 105).
} 
burocracia (e, particularmente, a sua dimensão de impessoalidade), as visões tecnicistas de uma razão instrumental quer do ensino, quer da aprendizagem, as lógicas de dominação e subalternização dos diferentes capitais ou poderes, as práticas produzidas pelos habitus gerados pela escola de acordo com a cultura considerada legítima, o carácter universal da cultura escolar, as práticas de disciplina e controlo, a etiquetagem moral e académica dos alunos, a ideologia meritocrática, o individualismo na realização pessoal e privatista, a conformidade e passividade face à autoridade, ou ainda, e de modo mais pragmático, as práticas de selecção na organização de turmas, o processo de ranking...

Por conseguinte, num primeiro momento, devia exercitar-se uma ética da denúncia de lógicas colonizadoras ou instrumentalizadoras (a favor de alguns), pouco consentâneas com a educação, designamente as que decorrem do mundo industrial e do mercado, e que tendem a invocar a excelência da gestão empresarial ou da gestão privada em nome, por exemplo, de "uma cultura do rendimento" (Whitty et al., 1999), omitindo ou menosprezando a justiça do mundo cívico que aponta para o facto de as escolas justas deverem ser pensadas sobretudo como escolas "para serem desejadas mais do que para serem bem geridas", dado que a "democracia e justiça são mais importantes que a gestão e o controlo” (Ward, 1994: 24).

Para além da ética da crítica, e tendo em vista promover uma ordem social justa na escola, haveria que avançar para uma "ética da justiça", respondendo esta mais explicitamente às questões da justiça como reconhecimento e libertação das relações opressivas, da igualdade, da autonomia, do bem comum, da participação democrática e dos direitos humanos. Tratar-se-ia de exercitar uma política da justiça que deveria levar a colocar o outro em posição de exprimir os seus direitos de um modo que não colidisse com a expressão dos direitos dos outros actores. Em termos mais explícitos, a questão da justiça deveria implicar, então, a construção de uma civilidade escolar assente em direitos e deveres capazes de reorganizar a experiência escolar, a luta pelo reconhecimento da alteridade, a clarificação de valores, a resolução negociada de conflitos, a prevalência da razão comunicativa nos processos de tomada de decisão...

Poderíamos acrescentar a esta lista, dentro da compreensão da pluralidade das gramáticas de justiça, a mobilização de uma competência ética esclarecida que, embora reconhecendo o valor do compromisso negociado e consciente entre as lógicas dos vários mundos que compõem a organização educativa e reconhecendo ainda a necessidade de se praticar a "igualdade complexa" no sentido de Walzer, ou seja, respeitando a relação de não-dominação recíproca entre as várias esferas da justiça (impedindo-se 
assim a interferência e predomínio de um único critério distributivo sobre os arranjos distributivos de outras esferas), realçaria, na luta pela construção da civilidade interna da escola, a sobredeterminação dos princípios de justiça do mundo cívico, não obstante as contradições que internamente também por ele perpassam.

Finalmente, pensamos que esta ética da justiça deveria completar-se com uma ética dialógica da responsabilidade que, segundo Cortina (1993: 220), "obriga, desde logo, a informar-se para tomar decisões correctas, dentro do humanamente possível" e que deve, acrescentamos, privilegiar os imperativos da razão emancipatória (que não meramente comunicativa), sensível às políticas diferenciadas da diferença, às práticas micro-emancipatórias, enfim, à ética do cuidado.

Isto significa que a educação deve assumir-se claramente como uma arena política, potenciando em todos os seus aspectos uma ética "baseada nos princípios da democracia, da solidariedade e da esperança” (Giroux, 1993: 128-9), propiciando aos actores educativos, e mormente aos seus responsáveis, a braços com uma multiplicidade de princípios de acção, o exercício de uma "autoridade emancipatória" que reconstrua democraticamente as relações entre "conhecimento, poder e desejo" e que reforce atitudes fundamentadas contra as formas de opressão, "tratando os alunos como se também estes devessem preocupar-se com as questões da justiça social e da acção política" (ibid.: 147). Por outras palavras, há que integrar a escola na lógica do agir comunicativo e emancipatório, visando reintroduzir, segundo a proposta de um "multiculturalismo revolucionário" de McLaren (2000), a preocupação pela ética, tornada "obsoleta" pelo capitalismo e "engolida pela terrível beleza da reificação" (ibid.: 14).

A nova ética, destranscendentalizada, proposta por este autor deve ser baseada na prática concreta e nas relações dialógicas, numa "pedagogia que resgata o outro". O multiculturalismo revolucionário é então um conceito fundamental da pedagogia da libertação, capaz de fornecer a consciência crítica mas também o desejo de lutar não apenas pela justiça económica mas também pela justiça nas "arenas políticas de raça, gênero e sexualidade" (ibid:: 286), tendo em conta ainda que todas essas relações, uma vez postas em marcha, se condicionam mutuamente. Obviamente que o reconhecimento das relações complexas e não-sincrónicas entre estas diferentes categorias sociais não pode fazer-nos esquecer que existem injustiças inerentes ao próprio sistema capitalista ou que decorrem das suas estruturas de opressão. Talvez seja necessário, então, mobilizar a concepção multidimensional de justiça de Young (1999), quando esta nos propõe a definição de justiça como "libertação das relações de opressão". 


\section{Conclusão}

Não obstante a riqueza dos contornos com que se tem revestido a polémica da justiça e dos desafios que tem colocado aos pressupostos filosóficos e políticos de muitos de nós, parece-nos que, face à evolução das sociedades actuais, ao pluralismo que caracteriza a democracia moderna e à necessidade da sua regulação fundamentada em princípios mínimos consensualmente negociados e aceites que assegurem a convivência e a democracia políticas, é razoável defender a elaboração de uma concepção política de justiça que torne reais a liberdade e a igualdade, em vez de se procurarem princípios verdadeiros e a-históricos de bem.

A justiça entendida como "institucionalização da igualdade e da liberdade" pode, na verdade, "servir de marco para determinar que concepções particulares de bem são aceitáveis” (Mouffe, 1999: 71), o que não invalida a posição dos que afirmam a prioridade ontológica do bem sobre o direito (isto significa que se distingue aqui claramente o plano da ética do plano da política, distinção iniciada na modernidade) nem mesmo a prioridade política desse mesmo bem comum desde que entendido como "bem comum político do regime democrático liberal" assente nos princípios da igualdade e da liberdade (ibid.: 72). Trata-se, pois, de uma teoria mínima de bem, que os defensores do liberalismo político, aliás, tendem a não rejeitar também.

Por outro lado, também pensamos que, independentemente de definições a priori de justiça porventura aceites universalmente, ela adquire especificidades de acordo com a comunidade política concreta e mesmo com as filosofias políticas que se perfilham. Neste sentido, as críticas ao princípio distributivo entendido na sequência de uma concepção universalista de justiça como equidade ou, se quisermos, como justiça de baixa intensidade (uma vez que fica reduzida à distribuição de recursos, a um certo privatismo e individualismo), justifica-se plenamente, ganhando mais força então a noção, também ela problemática, de justiça complexa.

Aplicada à educação, e mais particularmente às organizações educativas, esta noção de justiça permite dar conta do seu carácter compósito e compreender as diferentes lógicas argumentativas da acção concreta que perpassam pelas nossas escolas enquanto organizações, enquanto sistemas e enquanto mundos de vida. No entanto, o reconhecimento desta pluralidade, ainda que do ponto de vista analítico possa ser aliciante, não pode, de modo nenhum, ofuscar as suas debilidades ou omitir o compromisso com formas mais politizadas e emancipatórias de justiça (embora deva reconhecer-se que as nossas escolas ainda não são verdadeiramente "cidades" políticas). Talvez estejamos no domínio da "utopia educativa" que 
reivindica, no dizer de Terrén (2001), uma nova racionalidade, a "racionalidade dialógica", que não renega a universalidade mas que deverá estar sempre aberta "à negociação das particularidades da diferença" (Harvey, 1996: 362).

\section{Referências Bibliográficas}

Bauman, Zygmunt (1992), Intimations of Postmodernity. London: Routledge.

Boltanski, Luc; Thévenot, Laurent (1991), De la justification. Les économies de la grandeur. Paris: Gallimard.

Bourdieu, Pierre (1989), O poder simbólico. Lisboa: Difel.

Bourdieu, Pierre (1998), Escritos de educação. Vozes: Petrópolis.

Bourdieu, Pierre; Passeron, Jean-Claude (s/d), A reprodução. Lisboa: Vega.

Bourdieu, Pierre; Passeron, Jean-Claude (1964), Les héritiers. Paris: Minuit.

Burbules, Nicholas; Lord, Brian (1981), "Equity, Equal Opportunity, and Education", Educational Evaluation e Policy Analysis, 4(2), 169-187.

Carens, Joseph (1995), "Complex Justice, Cultural Difference, and Political Community", in David Miller; Michael Walzer (orgs.), Pluralism, Justice, and Equality. Oxford: Oxford UP, 45-66.

Connell, Robert (1995), "Pobreza e educação", in Pablo Gentili (org.), Pedagogia da exclusão. Crítica ao neoliberalismo em educação. Petrópolis: Vozes, 11-42.

Connell, Robert (1997), Escuelas y justicia social. Madrid: Morata.

Cortina, Adela (1993), Ética aplicada y democracia radical. Madrid: Tecnos.

Cunningham, Frank (2002), Theories of Democracy. A Critical Introduction. London: Routledge.

Davies, Lynn (1990), Equity and Efficiency? School Management in an International Context. London: The Falmer Press.

Derouet, Jean-Louis (1992), École et justice. De l'égalité des chances aux compromis locaux?. Paris: Éditions Anne-Marie Métailié.

Derouet, Jean-Louis (org.) (2000), L'école dans plusiers mondes. Bruxelles: De Boeck e Larcier.

Dubet, François (1999), "Sentiments et jugements de justice dans l'éxperience scolaire", in Denis Meuret (org.), La justice du système éducatif. Paris: De Boeck Université, 177-194.

Dubet, François (2001), “As desigualdades multiplicadas”, Revista Brasileira de Educação, $17,5-19$.

Dubet, François; Martuccelli, Danilo (1996), A l'école: Sociologie de l'expérience scolaire. Paris: Seuil.

Elster, Jon (1995), "The Empirical Study of Justice”, in David Miller; Michael Walzer (orgs.), Pluralism, Justice, and Equality. Oxford: Oxford UP, 81-98. 
Estêvão, Carlos V. (1998), Redescobrir a escola privada portuguesa como organização. $\mathrm{Na}$ fronteira da sua complexidade organizacional. Braga: Instituto de Educação e Psicologia da Universidade do Minho, 1998.

Estêvão, Carlos V. (2001), Justiça e educação. S. Paulo: Cortez.

Estêvão, Carlos V. (2002), Globalização, metáforas organizacionais e mudança educacional. Porto: Asa.

Flecha, Ramón (1994), "Las nuevas desigualdades educativas" in Manuel Castells et al., Nuevas perspectivas críticas en educación. Barcelona: Paidós Educador, 55-82.

Fraser, Nancy (1997), Justice Interruptus: Critical Reflections on the 'Postsocialist' Condition. London: Routledge.

Frétigné, Cédric (1999), Sociologie de l'exclusion. Paris: L'Harmattan.

García-Marzá, V. Domingo (1992), Ética de la justicia. Madrid: Tecnos.

Gewirtz, Sharon (1998), "Conceptualizing Social Justice in Education: Mapping the Territory”, Journal of Education Policy, 13(4), 469-484.

Giroux, Henry (1993), La escuela y la lucha por la ciudadania. Madrid: Siglo Veintuno Editores.

Habermas, Jürgen (1987), Teoría de la acción comunicativa. Crítica de la razón funcionalista. Madrid: Taurus.

Habermas, Jürgen (1997), Droit et démocratie. Entre faits et normes. Paris: Gallimard. Habermas, Jürgen (2001), Facticidade y validez. Madrid: Ed. Trotta.

Harvey, David (1996), Justice, Nature and the Geography of Difference. Oxford: Blackwell. Hogan, David (1997), "The Logic of Protection: Citizenship, Justice and Political Community", in Kerry Kennedy (org.), Citizenship Education and the Modern State. London: The Falmer Press, 27-53.

Ledesma, M. Pérez (2000), "Ciudadanos y ciudadanía. Un análisis introductorio", in M. Pérez Ledesma (org.), Ciudadanía y democracía. Madrid: Ed. Pablo Iglésias, 1-35. Lynch, Kathleen (1995), "The Limits of Liberalism for the Promotion of Equality in Education", in Association for Teacher Education in Europe (20th Annual Conference, Oslo, 3-8 September).

McCarthy, Cameron (1988), "Rethinking Liberal and Radical Perspectives on Racial Inequality in Schooling: Making the Case for Nonsynchony", Harvard Educational Review, 58(3), 265-279.

McLaren, Peter (2000), Multiculturalismo revolucionário. Pedagogia do dissenso para o novo milênio. Porto Alegre: Artes Médicas.

Meuret, Denis (1999a), "Introduction”, in Denis Meuret (org.), La justice du système éducatif. Paris: De Boeck Université, 7-16.

Meuret, Denis (1999b), "Rawls, l'éducation et inégalité des chances”, in Denis Meuret (org.), La justice du système éducatif. Paris: De Boeck Université, 37-54.

Miller, David (1995), "Introduction”, in David Miller; Michael Walzer (orgs.), Pluralism, Justice, and Equality. Oxford: Oxford UP, 1-16. 
Mouffe, Chantal (1999), El retorno de lo político. Barcelona: Paidós.

Nogueira, C. Marques; Nogueira, M. Alice (2002), “A sociologia da educação de Pierre Bourdieu: Limites e contribuições”, Educação e Sociedade, XXIII(78), 15-36.

Parker, Lawrence; Shapiro, Joan (1993), "The Context of Educational Administration and Social Class", in Colleen Capper (org.), Educational Administration in a Pluralistic Society. New York: State University of New York Press, 36-65.

Perelman, Chaim (1990), Ethique et droit. Bruxelles: Ed. de l'Université de Bruxelles.

Rawls, John (1993), Uma teoria da justiça. Lisboa: Presença.

Santos, Boaventura de Sousa (2000), A crítica da razão indolente. Contra o desperdício da experiência. Porto: Afrontamento.

Starratt, Robert (1991), "Building an Ethical School: A Theory for Practice in Educational Leadership”, Educational Administration Quarterly, 27(2), 185-202.

Starratt, Robert (1994), Building an Ethical School. London: The Falmer Press.

Stoer, Sephen; Cortesão, Luísa (1999), "Levantando a pedra". Da pedagogia inter/ multicultural às políticas educativas numa época de transnacionalização. Porto: Afrontamento.

Sturman, Andrew (1997), Social Justice in Education. Camberwell: Acer Press.

Terrén, Eduardo (2001), "A educação face aos desafios da pós-modernidade”, in Teresa Ambrósio et al., O século da escola. Entre a utopia e a burocracia. Porto: Asa Editores, 9-39.

Thévenot, Laurent (1992), "Un pluralisme sans relativisme?. Théories et pratiques du sens de la justice”, in Joelle Affichard; Jean-Baptiste de Foucauld (orgs.), Justice sociale et inégalités. Paris: Éd. Esprit, 221-253.

Touraine, Alain (1996), O que é a democracia?. Petrópolis: Vozes.

Walzer, Michael (1999), As esferas da justiça. Em defesa do pluralismo e da igualdade. Lisboa: Editorial Presença.

Ward, James G. (1994), "Reconciling Educational Administration and Democracy: The Case for Justice in Schools", in Nona A. Prestine; Paul W. Thurston (orgs.), Advances in Educational Administration, vol. 3. London: JAI Press Inc., 1-27.

Whitty, Geoff et al. (1999), La escuela, el estado y el mercado. Madrid: Morata.

Young, Iris (1990), Justice and the Politics of Difference. Princeton: Princeton UP. 